\title{
Drug Taking in Adolescent Girls: Factors Associated With the Progression to Narcotic Use
}

\author{
PETER NOBLE, GILL GORELL BARNES
}

British Medical fournal, 1971, 2, 620-623

\section{Summary}

A follow-up study of girls in a London remand home during the years 1966-8 showed that $20.6 \%$ of those taking non-narcotic drugs on admission, but only $1 \%$ of non-drug-taking control admissions, had used narcotics by June 1970. Narcotic use on admission and progression to narcotic use were associated with frequent drug taking, marked involvement in a drug milieu, and a high incidence of personal morbidity. Adolescents who use illicit drugs and have a history of court appearances for any reason are particularly vulnerable to subsequent narcotic usage and other forms of serious drug abuse.

\section{Introduction}

Though the illicit use of drugs by young people has become increasingly common, few studies have related the characteristics of these drug takers to their subsequent progress. In particular the connexion between the relatively widespread use of non-narcotic drugs, such as cannabis and amphetamines, and the more dangerous use of narcotic and intravenous drugs remains ill-documented and controversial (Department of Health and Social Security, 1970). Almost all narcotic users have previously used non-narcotic drugs, but the high ratio of non-narcotic to narcotic use indicates that only a minority progress in this way.

A survey of delinquent boys (Noble, 1970) showed that $19 \cdot 1 \%$ of those taking non-narcotic drugs had progressed to narcotic taking within a three-year period. These "progressors" tended to show a higher incidence of personal and psychiatric morbidity than the other drug takers, but the number was too small for detailed comparisons.

This paper presents the results of a similar study on delinquent girls. An attempt is made to extend earlier work by delineating more precisely the characteristics of those who progress to narcotic use.

\section{Subjects}

The subjects of this study were adolescent girls admitted for court reports to a London remand home during the years 1966-8. During this time the staff attempted to identify all girls who had taken illicit drugs in the month before admission. These girls were questioned about their drug-taking habits and further information was available from court and social records. Where possible the urine of girls suspected of drug taking was tested. Of about 1,000 girls 194 had used nonnarcotic drugs and a further 33 had also used narcotics.

The 227 drug-taking girls and 100 control admissions were then followed up to discover the incidence of subsequent narcotic use. Data were obtained to June 1970, so that the mean length of follow-up was three years. Personal inquiries were

Maudsley Hospital, London S.E.5

PETER NOBLE, M.D., M.R.C.P., Senior Registrar

GILL GORELL BARNES, M.A., M.SC., Psychiatric Social Worker made to social and medical agencies dealing with the subjects. Home Office drug records, mental hospital records, and criminal records were obtained and analysed. With these sources it was possible to trace about $90 \%$ of the subjects (Noble, Hart, and Nation, 1971). These data provided evidence that 40 of the 194 non-narcotic users, but only one of the 100 controls used narcotics during the follow-up period.

This information was then used to subdivide 90 of the subjects into three groups of 30 girls matched for age and year of admission. These categories were: narcotic group, girls taking narcotics on admission; progressor group, girls taking non-narcotic drugs on admission who used narcotics during the follow-up period; and non-progressor group, girls taking non-narcotic drugs at admission who did not subsequently use narcotics. The mean ages of the three groups were respectively $16 \cdot 2$ (S.D. 0.76), $16 \cdot 1$ (S.D. $0 \cdot 67$ ), and $16 \cdot 1$ (S.D. $0 \cdot 65$ ) years.

Before admission the drugs taken by the girls were: nonprogressor group-amphetamine 24, cannabis 20, methylamphetamine 3, L.S.D. 2; progressor group-amphetamine 24, cannabis 18, methylamphetamine 3, L.S.D. 2; and narcotic group-heroin 28, cocaine 8 , methadone 5 , morphine 2, amphetamine 27 , cannabis 24 , methylamphetamine 16 , L.S.D. 6. The pattern of drug taking, particularly in the narcotic group, was often one of multiple and indiscriminate drug abuse. In addition to the drugs listed, some girls had taken barbiturates and tranquillizers when available. The narcotic group had taken more types of drug (mean 5.2) than either the nonprogressors (mean $2 \cdot 1, t=8.3, \mathrm{P}<0.001$ ) or the progressors (mean 2.3, $t=7.4, \mathrm{P}<0.001$ ). All the narcotic group had used intravenous drugs and over half had injected themselves with methylamphetamine. Three of the non-progressors and two of the progressors had also used intravenous methylamphetamine. Subsequently the progressors used in addition: heroin 27 , cocaine 5, methadone 12, and narcotics (unspecified) 2 . Like the girls on narcotics on admission they tended to multiple drug abuse and all used drugs intravenously. By the end of the follow-up period methylamphetamine was virtually unobtainable but the intravenous use of barbiturates was increasing.

\section{Methods}

The usual length of remand was two to three weeks. During this time reports were prepared by the house staff and teachers at the remand home, a psychologist, and a psychiatrist. All subjects were medically examined and previous court and school records were obtained. Further information was usually available in reports prepared by a psychiatric social worker, probation officers, and the local child care department. Items of data related to these assessments and to drug taking were then coded and recorded on punched cards by the remand home staff. These data were supplemented by a retrospective analysis of all case notes and used to rate each subject on a standard item sheet devised from a previous drug survey (Noble, 1970). A random sample of 15 of the subjects was then rated independently. The between-rater correlation coefficient was $8 \cdot 0$.* $^{*}$

In a survey of this type is was inevitable that many of the home staff knew about the girls' drug taking and this could

Kappa $=\frac{P_{o}-P_{c}}{1-P_{c}}$ 
theoretically have biased their assessments. However, neither the staff nor the one of us (G.G.B.) rating the item sheets had previous access to the information distinguishing the non-progressor from the progressor group.

The categories non-progressor, progressor, and narcotic fall into a natural order. It was thus appropriate to subdivide the overall $\chi^{2}$ values in a way that enabled the component of $\chi^{2}$ due to linear trends to be separated out and tested for significance (Maxwell, 1961).

\section{Results}

\section{FREQUENCY OF DRUG TAKING}

The mean frequencies of drug use for the three categories are given in Table I. Narcotic use and progression were associated with more frequent drug taking. The multiplicity of drugs used made it more difficult to quantify the information collected about drug dosage. However, inspection of the data suggested that those girls using drugs most frequently also took the highest dosage.

TABLE I-Mean Frequency of Drug Taking

\begin{tabular}{lll|c|c|c}
\cline { 4 - 6 } & & & $\begin{array}{c}\text { Non- } \\
\text { progressor }\end{array}$ & Progressor & Narcotic \\
\hline \begin{tabular}{lll|c|c} 
Less than weekly \\
1-3 days weekly
\end{tabular} & $\ldots$ & $\ldots$ & 18 & 12 & 1 \\
More than 3 days weekly & $\ldots$ & $\ldots$ & 12 & 9 & 14 \\
\hline
\end{tabular}

Linear $\chi^{2}=28.2 ; \mathrm{P}<0.001$

\section{INVOLVEMENT IN DRUG MILIEU}

The time each girl spent in the company of other drug users, frequenting places where drugs were available, and in obtaining and taking drugs was used to rate her involvement in a drug milieu on a three-point scale (Table II). There was a pronounced trend for the progressor and narcotic groups to be more involved in a drug milieu.

TABLE II-Involvement in Drug Milieu

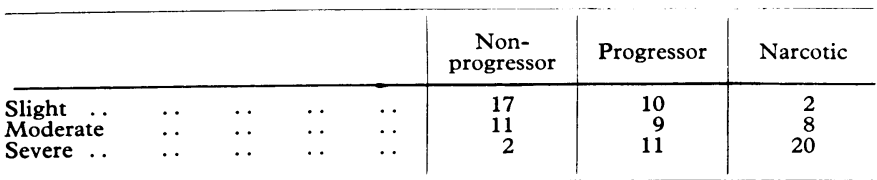

Linear $\chi^{2}=26.4 ; P<0.001$

\section{SYMPTOMS ON ADMISSION}

On admission the remand home and medical staff noted any symptoms attributable to drug taking or intoxication. The number of girls displaying such symptoms was: non-progressor 10 , progressor 14, and narcotic 22. These differences are significant (linear $\chi^{2}=9.6 ; \mathrm{P}<0.005$ ) and provide some objective confirmation of the trend towards frequent and heavier drug taking among the progressor and narcotic groups.

\section{FAMILY SITUATION}

When possible a psychiatric social worker interviewed the mother at the remand home; otherwise information about the family was taken from child care or probation reports. These data did not permit the families to be described in detail but did provide some information about the subjects' upbringing and relationship with their parents.

The occupations of the girls' fathers or of the mother if the father was permanently absent are given in Table III. The recorded incidences in the case notes of items related to morbidity within the family are shown in Table IV. There is no sharp distinction between the backgrounds of the different types of drug user; rather, a consistent pattern emerges common to all three groups.
TABLE III-Socioeconomic Status ${ }^{*}$

\begin{tabular}{|c|c|c|c|c|}
\hline Class & & $\begin{array}{c}\text { Non- } \\
\text { progressor }\end{array}$ & Progressor & Narcotic \\
\hline $\begin{array}{l}\text { I. Professional, etc. . } \\
\text { II. Intermediate } \\
\text { III. Skilled } \\
\text { IV. Partly skilled } \\
\text { V. Unskilled ... }\end{array}$ & $\begin{array}{ll}\cdots & \cdots \\
\cdots & \cdots \\
\cdots & \cdots \\
\cdots & \cdots \\
\cdots & \cdots\end{array}$ & $\begin{array}{r}0 \\
1 \\
11 \\
8 \\
5\end{array}$ & $\begin{array}{r}0 \\
2 \\
11 \\
2 \\
5\end{array}$ & $\begin{array}{r}0 \\
3 \\
13 \\
3 \\
3\end{array}$ \\
\hline
\end{tabular}

*The classification is based on the occupation of the head of the family (Genera Register Office, 1966) when this information was available.

TABLE IV-Family Situation

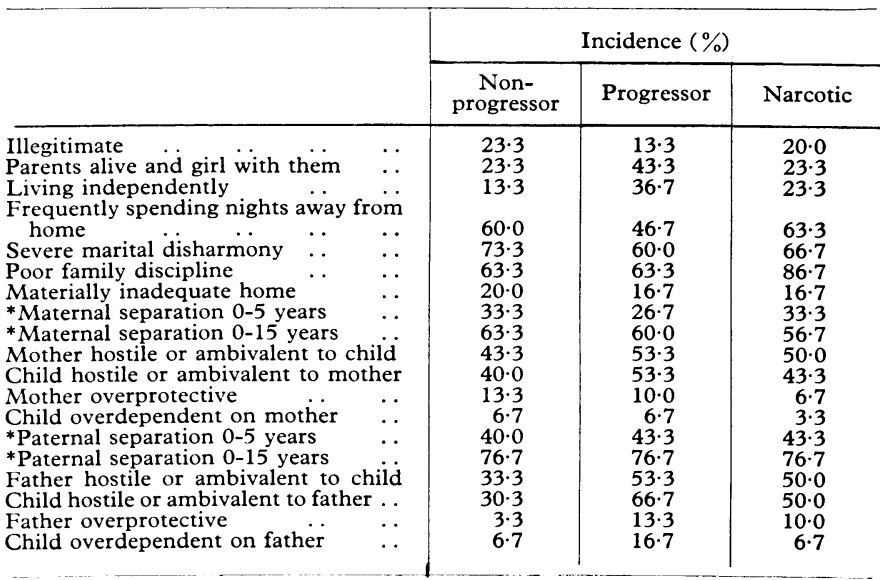

*Separation for a period of six weeks or more.

Most girls came from homes which were materially adequate and had parents who worked in skilled or semi-skilled jobs. These families were characterized by disruption, parental separation, poor discipline, and hostility. Only a minority of the girls were still living with both parents. Many of the girls who were living independently were in squalid or unsupervised circumstances, and a high proportion of those nominally living with families, or in hostels, were often absent all night.

Moreover, the reports often indicated that the parents themselves had abnormal personalities, were unhappy, or had difficulty in coping with life. The recorded incidence of abnormal personality traits among the subjects' mothers was: nonprogressor group $53.6 \%$, progressor group $57 \cdot 7 \%$, and narcotic group $52.0 \%$, whereas among the fathers these incidences were $27.2 \%, 63.2 \%$, and $64.7 \%$ (linear $\chi^{2}=5.8 ; \mathrm{P}<0.025$ ) respectively. There was also a high incidence of unemployment among the fathers: non-progressor group $13.6 \%$, progressor group $21.1 \%$, and narcotic group $29.4 \%$. It is of interest that the progressor and narcotic groups showed a higher incidence of hostility between the subjects and their fathers. There was little evidence of overprotection or overdependence in any of the three groups.

\section{SIBLINGS}

The girls tended to come from large families. The mean number of siblings per subject was: non-progressor group 3.5, progressor group 3.4, and narcotic group 3.4. The mean age in years of the siblings in each group was respectively $14 \cdot 2,15 \cdot 7$, and 14.7. Personal data on the siblings were incomplete but 32 of the non-progressor group siblings, 25 of the progressor group, and 27 of the narcotic group were recorded as having either juvenile court convictions or as being known to the local authorities to be in need of care.

\section{IMMIGRATION}

Only two girls-one from the West Indies and one from Germany-were born outside the British Isles. However, a high proportion of girls had at least one parent who was either immigrant or who had grown up in Ireland (non-progressor group $33.3 \%$, progressor group $45.0 \%$, and narcotic group 
$36.7 \%$ ). Eight of these girls were of West Indian origin; in 13 at least one parent was a first-generation European immigrant and in 11 at least one parent had been brought up in Ireland.

\section{JUVENILE COURT RECORDS}

The previous court appearances of the subjects are shown in Table V. Eight of the non-progressor group, 11 of the progressors, but only two of the narcotic group had no previous appearances. "Being in need of Care, Protection or Control," "Refractory to Supervision," or a "Fit Person Order" are not of themselves evidence that the subject has broken the law. In practice the distinction between the "in need of care" and "delinquent" categories is less clear cut. The police exercise a considerable, but informal, discretion in whom they charge. Thus some girls placed under "Supervision" or a "Fit Person Crder" were not charged with offences, even though these were known. Presumably it was felt that the powers already possessed for their care and control were sufficient. Equally it often seemed that some girls charged with offences were charged, in part at least, because other aspects of their way of life or situation seemed to the police to be unsatisfactory or in need of supervision. Only five previous convictions were for drug offences.

TABLE v-Fuvenile Court Records

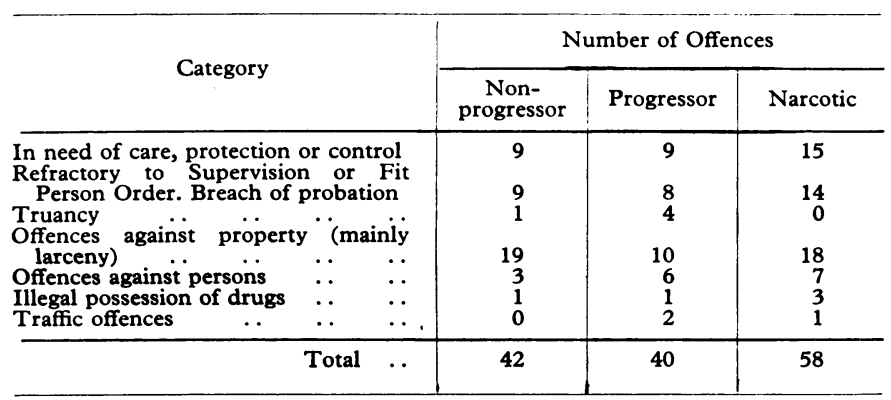

\section{PSYCHIATRIC MORBIDITY}

The recorded incidence of personality disorder and psychiatric morbidity is shown in Table VI. The progressor and narcotic groups tended to have a higher incidence of morbidity in all categories. The personality abnormalities were generally of long standing and antedated the onset of drug taking. The personality disturbance of the subjects in the progressor and narcotic groups tended to be particularly severe and incapacitating. These girls were often highly anxious, had few friends outside a drug milieu, were impulsive, tolerated stress poorly, and easily became depressed or aggressive. Many subjects had been referred to psychiatrists, but specialized treatment for drug taking was uncommon, except for those on narcotics. The incidence of recent depressive symptomatology and suicidal attempts among the narcotic group was particularly high. Three girls on narcotics were transferred from the remand home for inpatient psychiatric care and two girls, subsequently injecting narcotics, died from drug overdosages.

TABle vi-Personality and Previous Psychiatric Morbidity

\begin{tabular}{|c|c|c|c|c|c|}
\hline & $\begin{array}{c}\text { Non-pro- } \\
\text { gressor }\end{array}$ & $\begin{array}{l}\text { Pro- } \\
\text { gressor }\end{array}$ & $\begin{array}{l}\text { Nar- } \\
\text { cotic }\end{array}$ & $\underset{\chi^{2}}{\operatorname{Linear}}$ & $\mathbf{P}$ \\
\hline $\begin{array}{l}\text { Abnormal personality } \\
\text { Depressive symptomatology }\end{array}$ & 18 & 27 & 28 & $10 \cdot 9$ & $<0.001$ \\
\hline $\begin{array}{l}\text { (past year) } \\
\text { Previous psychiatric or child }\end{array}$ & 7 & 8 & 17 & $7 \cdot 3$ & $<0.01$ \\
\hline $\begin{array}{cc}\text { guidance referral } & \ldots \\
\text { Previous suicide attempt } & \ldots\end{array}$ & $\begin{array}{r}14 \\
6\end{array}$ & $\begin{array}{r}19 \\
3\end{array}$ & 23 & $\begin{array}{l}5 \cdot 7 \\
9 \cdot 8\end{array}$ & $\begin{array}{l}<0.025 \\
<0.005\end{array}$ \\
\hline $\begin{array}{ccc}\text { Previous treatment for drug } \\
\text { taking }\end{array}$ & 1 & 0 & 9 & $10 \cdot 8$ & $<0.005$ \\
\hline
\end{tabular}

\section{SEXUAL HISTORY}

A high proportion of the girls had experienced sexual intercourse (non-progressors $73.3 \%$, progressors $73.3 \%$, and narcotic group $83.4 \%$ ). Narcotic taking was associated with a higher incidence of venereal disease (non-progressors $26.6 \%$, progressors $26.6 \%$, and narcotic group $50.0 \% ; \chi^{2}=5.6 ; \mathrm{P}<0.025$ ).

\section{SCHOOL ASSESSMENTS}

Reports from the girls' schools were used to rate them on a three-point scale for truancy, behaviour, and quality of school work. The results of these ratings are given in Table VII. A tendency for the progressor and narcotic groups to score worse than the non-progressor group did not reach statistical significance.

TABLE VII-School Assessment

\begin{tabular}{|c|c|c|c|c|c|}
\hline & & & $\begin{array}{c}\text { Non- } \\
\text { progressor }\end{array}$ & Progressor & Narcotic \\
\hline Truancy & .. & $\left\{\begin{array}{l}\text { None } \\
\text { Occasional } \\
\text { Frequent }\end{array}\right.$ & $\begin{array}{r}12 \\
3 \\
15 \\
\end{array}$ & $\begin{array}{r}8 \\
4 \\
18\end{array}$ & $\begin{array}{r}6 \\
8 \\
16\end{array}$ \\
\hline Behaviour & .. & $\left\{\begin{array}{l}\text { Good } \\
\text { Average }\end{array}\right.$ & $\begin{array}{r}5 \\
12\end{array}$ & $\begin{array}{r}0 \\
10\end{array}$ & $\begin{array}{r}2 \\
10\end{array}$ \\
\hline & & $\begin{array}{l}\text { Poor } \\
\text { Good }\end{array}$ & $\begin{array}{r}13 \\
3\end{array}$ & $\begin{array}{r}20 \\
2\end{array}$ & $\begin{array}{r}18 \\
2\end{array}$ \\
\hline School work & .. & $\left\{\begin{array}{l}\text { Average } \\
\text { Poor }\end{array}\right.$ & $\begin{array}{l}10 \\
17\end{array}$ & $\begin{array}{l}10 \\
18\end{array}$ & $\begin{array}{r}7 \\
21\end{array}$ \\
\hline
\end{tabular}

An increased proportion of girls in the progressor and narcotic groups had attempted some form of higher education which involved staying beyond the normal school-leaving age (non-progressor 2, progressor 6, and narcotic 9; linear $\chi^{2}=5 \cdot 3$; $P<0.025)$. The educational aspirations of the narcotic takers were generally unsuccessful. Six out of nine had broken off their studies without passing any examinations. Psychological testing showed no difference in intelligence between the different categories (non-progressors 98.4 $\pm 16 \cdot 7$, progressors $101 \pm$ $13 \cdot 9$, and narcotic $97 \cdot 9 \pm 15 \cdot 2$ ).

\section{WORK RECORD}

Nineteen girls in the non-progressor and progressor groups and 22 in the narcotic group had left school and attempted some form of employment. Girls who were unable to hold a job, had frequent changes of employment, or had periods of unemployment were rated as having unstable work records. The work records of these subjects are given in Table VIII. There was a significant association between having an unstable work record and progression and narcotic use. However, the work histories of all three categories were poor, and only a minority of girls, even in the non-progressor group, had stable work records.

TABLE VIII-Work Record

\begin{tabular}{lll|c|c|c}
\hline & & $\begin{array}{c}\text { Non- } \\
\text { progressor }\end{array}$ & Progressor & Narcotic \\
\hline $\begin{array}{l}\text { Stable work record } \\
\text { Unstable work record }\end{array}$ & $\ldots$ & $\ldots$ & 11 & 17 & 20 \\
\hline
\end{tabular}

Linear $\chi^{2}=6.0 ; P<0.025$.

\section{REMAND HOME ASSESSMENT}

Reports prepared by teachers and house staff were used to rate the subjects on a three-point scale for relationships with other girls, discipline, and concentration and persistence at

TABLE IX-Remand Home Assessment

\begin{tabular}{|c|c|c|c|c|}
\hline & & $\begin{array}{c}\text { Non- } \\
\text { progressor }\end{array}$ & Progressor & Narcotic \\
\hline $\begin{array}{l}\text { Interpersonal } \\
\text { relationships* } \\
\text { Discipline } \\
\text { Work* }\end{array}$ & $\begin{array}{l}\text { Good } \\
\text { Average } \\
\text { Poor } \\
\text { Good } \\
\text { Average } \\
\text { Poor } \\
\text { Good } \\
\text { Average } \\
\text { Poor }\end{array}$ & $\begin{array}{r}9 \\
13 \\
8 \\
9 \\
17 \\
4 \\
8 \\
17 \\
5\end{array}$ & $\begin{array}{r}4 \\
8 \\
18 \\
9 \\
12 \\
9 \\
7 \\
11 \\
12\end{array}$ & $\begin{array}{r}3 \\
10 \\
17 \\
10 \\
8 \\
12 \\
4 \\
11 \\
15\end{array}$ \\
\hline
\end{tabular}

$* \mathrm{P}<0.025$. Linear $\chi^{2}>5.02$ 
school and domestic work (Table IX). There was a significant trend for subjects in the progressor and narcotic groups to have poor in terpersonal relationships and to work badly.

\section{Discussion}

Subjects remanded by the courts form a small, and presumably atypical, minority of their age group. There is, however, increasing evidence that this type of background is common among narcotic users. Recent surveys in this country have shown a clear association between delinquency, criminality, and narcotic use. D'Orban (1970) found that $60 \%$ of female "heroin addicts" in Holloway Prison had convictions before the onset of addiction and that a high proportion had been in approved schools or Borstal. Pierce James (1968) reported that $76 \%$ of addicts admitted to a London prison had convictions before addiction. This association is not limited to forensically orientated surveys. Gordon (1971), in a study of male attenders at an addiction clinic, found that $48 \%$ had convictions before their first drug use and $90 \%$ before attendance at the clinic. Hawks et al. (1969) reported that $65 \%$ of methylamphetamine users had previous convictions. Thus it would seem that most habitual narcotic users have previous convictions for non-drug offences and appear in court before presenting to medical agencies. An association between drug taking and deviant behaviour may also be found in less obviously disturbed groups. Webb (1969) reported that students who use cannabis have more criminal convictions than non-drug users.

In spite of the statistical association between delinquency, criminality, and drug taking there is, with the obvious exception of drug offences, no clear evidence of a causal relationship. Many of the subjects in this study had been delinquent before taking drugs. Moreover, inspection of our data did not suggest either that offences were particularly likely to be committed while intoxicated or that most acquisitive offences were directly related to the need to obtain money to buy drugs. Rather, it seems that both the drug taking and the offences committed reflect the difficulty these girls had in conforming to the requirements of society.

The family backgrounds of all three groups of drug takers showed many common features. The families tended to be large, but not poverty-stricken, and to come from the middle of the social scale. Within these families, however, the incidence of disruption, inadequate care, parental deprivation, personality abnormality, and hostility was high. The overall incidence of family morbidity was higher than that shown in a similar study of drug-taking delinquent boys (Noble, 1970). This confirms the general finding that fewer females than males appear before the courts but that those who do are more disturbed. The pattern of family morbidity did not correlate with the type of drug taking, though the non-progressor group showed a lower incidence of mutual hostility between the girls and their fathers.

Pattern of drug taking change rapidly and do not conform to any simple stereotype, thus making cross-cultural comparisons difficult (Edwards, 1967). However, the rapid increase in drug taking by young people in this country and its association with delinquency prompts comparison with the American scene. These girls differed from many American urban narcotic addicts in that they did not come from family circumstances of poverty or squalor (Scher, 1966). However, they resembled them in showing a high incidence of family disintegration and poor parental care (Chein et al., 1964). In this country the use of intravenous or narcotic drugs is not particularly associated with coloured immigrants or with areas in which they predominate. It is of interest that though only nine girls in this sample were coloured a high proportion had parents who were born outside this country. These parents, though not necessarily subjected to racial prejudice, had to contend with the extra strain and pressure of bringing up a family in a culture and milieu often substantially different from that in which they were reared themselves.
The $20.6 \%$ progression rate to narcotic use was similar to the figure of $19.1 \%$ for non-progressor drug users in a boys' remand home (Noble, 1970). In assessing the significance of this progression it must be cautioned that these figures are probably underestimates. In both studies the period of follow-up was short and the method used was such that transitory or occasional narcotic use could have escaped detection.

Analysis of the data on the subjects themselves showed statistically significant differences between the non-progressor, progressor, and narcotic categories. Placed in this order the three categories showed a gradient of increasing morbidity. The items which were most effective in differentiating the three groups were those that were related to the pattern of drug taking. Thus the progressors, when compared with the non-progressors, tended to use drugs more frequently, be more involved in a drug milieu, and to be more likely to be suffering from the effects of drugs on admission. They also showed a higher incidence of personality abnormality before psychiatric referral and unstable work records. During their stay in the remand home their interpersonal relationships were poor, and they found it difficult to concentrate on academic and household tasks. The narcotic group showed all these traits but to a greater degree. The great anxiety, unhappiness, and despair among these girls is evidence by the high proportion who gave a history of recent depressive symptoms or had attempted suicide.

These comparisons are important because they go some way towards providing an answer to the vexed question of which of the many young people who use non-narcotic drugs are liable to subsequent narcotic usage and other serious drug abuse. The results confirm those of an earlier survey (Noble, 1970) and suggest that a young person who both uses illicit drugs and has a history of court findings, either for delinquency or for "being in need of care and protection," should be looked on as at considerable risk for future progression. This progression is not simply a correlate of delinquency or remand home admission, as only one out of 100 control admissions was discovered to have subsequently used narcotics. Moreover, this risk is not borne equally by all drug takers as, even on admission, there were significant mean differences between the progressor and non-progressor groups. These differences are thus of prognostic importance and may aid the identification at an early stage of those subjects who are most likely to be harmed by subsequent narcotic use. This narcotic use is not only serious in itself but is generally associated with multiple drug abuse and, more recently, with the intravenous injection of barbiturates.

The completion of this survey would not have been possible without the generous help and collaboration of the remand home staff. We should also like to thank Dr. D. V. Hawks, of the Institute of Psychiatry, and Mr. B. Spear, of the Home Office, for advice and assistance. This work was supported by a grant from the Nuffield Foundation.

\section{References}

Chein, I., Gerrard, D. L., Lees, R. S., and Rosenfeld, E. (1964). The Road to $H$. New York, Basic Books.

Department of Health and Social Security (1970). Report No. 124. Amphetamines, Barbiturates, LSD and Cannabis. London, H.M.S.O.

D.'Orban, P. T. (1970). British Fournal of Addiction, 65, 67.

Edwards, G. (1967). British Medical fournal, 3, 425.

General Register Office (1966). Classification of Occupations. London, H.M.S.O

Gordon, A. (1971). Patterns of delinquency in drug addiction. M. Phil. Dissertation, University of London.

Hawks, D., Mitcheson, M., Ogborne, A., and Edwards, G. (1969). British Medical fournal, 2, 715 .

Medical fournal, 2, 715.
James, I. P. (1968). British fournal of Criminology, 9, 108. Maxwell, A. E. (1961). Analysing Qualitative Data. London, Methuen.

Noble, P. J. (1970). British Medical fournal, 1, 102. Noble, P. J., Hart, T., and Nation, R. R. N. (1971). Drug taking in adolescent girls. Submitted for publication.

Scher, J. (1966). Archives of General Psychiatry, 15, 539.

Webb, M. G. T. (1969). Cannabis use in a student population. M. Phil. Dissertation, University of London. 